\title{
Numerical Simulations of a Buoyancy-Driven Coastal Countercurrent off Vancouver Island
}

\author{
Diane Masson and Patrick F. Cummins \\ Institute of Ocean Sciences, Sidney, British Columbia, Canada
}

(Manuscript received 2 June 1997, in final form 19 March 1998)

ABSTRACT

\begin{abstract}
A three-dimensional prognostic numerical model has been developed to study the ocean circulation around Vancouver Island, British Columbia. In a series of simulations, the model is applied to examine the role of buoyancy forcing in the dynamics of the summer coastal countercurrent found off the west coast of Vancouver Island. The forcing is provided by the Fraser River discharge into the Strait of Georgia. An estuarine circulation establishes itself in Juan de Fuca Strait, from which a distinctive right-bounded current is formed and advances along the coast. Sensitivity studies are conducted to determine the robustness of this current to initial conditions, opposing wind, enhanced vertical mixing, and grid resolution. Finally, various characteristics of the numerically modeled coastal flow are compared with observations.
\end{abstract}

\section{Introduction}

River discharge is an important forcing for the circulation in many regions of the coastal ocean. Typically, the freshwater enters the ocean environment through an estuary, whence it forms a plume and becomes a local source of momentum and buoyancy. Associated with the plume, a density current can form with the coastline to the right in the Northern Hemisphere. On the Canadian west coast, such a poleward flow over the shelf exists and is known as the Vancouver Island Coastal Current (VICC). It originates north of Juan de Fuca Strait and flows poleward along most of the coast of Vancouver Island (Fig. 1). During summer, this current flows counter to the prevailing northwesterly winds and to the wind-driven shelfbreak current (e.g., Freeland et al. 1984; Thomson et al. 1989). The main summertime source of freshwater for the area is the Fraser River which discharges into the Strait of Georgia. The river water reaches Juan de Fuca Strait where an estuarine circulation is established, typical of a partially mixed estuary. At the mouth of Juan de Fuca Strait, the plume debouches onto the shelf, and the associated buoyancy flux may be expected to play an important role in driving the summer coastal countercurrent (Hickey et al. 1991).

Various investigations have focused on the modeling of estuarine outflow onto the continental shelf. Csanady

Corresponding author address: Dr. Diane Masson, Institute of Ocean Sciences, P.O. Box 6000, 9860 West Saanich Rd., Sidney, BC V8L 4B2, Canada.

E-mail: massond@dfo-mpo.gc.ca
(1978) developed the arrested topographic wave model in which the estuarine influence is represented as a source of volume in a barotropic ocean with a straight coastline. In this model of coastally trapped, frictional flow, a concentrated source of freshwater can drive a coastal current of significant alongshore extent. Chao and Boicourt (1986) applied a three-dimensional, primitive equation model to study numerically the flow structure on an idealized shelf forced by an estuarine freshwater discharge. They clearly identified a density-driven, right-bounded current originating near the mouth of the estuary. Chao (1987) extended the latter study by including a spatially uniform alongshore wind. He found that an upwelling favorable wind can weaken the alongshore current and displace it offshore. More recently, sophisticated three-dimensional simulations have been applied to study plume dynamics and associated buoyancy-driven coastal currents over specific regions of the continental shelf. Kourafalou et al. (1996) used the Blumberg and Mellor (1987) model to simulate the response of the coastal circulation to buoyancy and wind forcing in the South Atlantic Bight. They found, associated with the plume, a coastal current flowing in the direction of Kelvin wave propagation. It was also established that a light, opposing wind stress does not significantly affect the coastal current, but that moderate to strong winds may fully reverse the buoyancy-driven current.

The VICC system has been the subject of two recent modeling studies. Foreman and Thomson (1997) used a diagnostic, finite-element model with a specified density field held fixed in time to estimate geostrophic flows off Vancouver Island. In such an approach, open bound- 


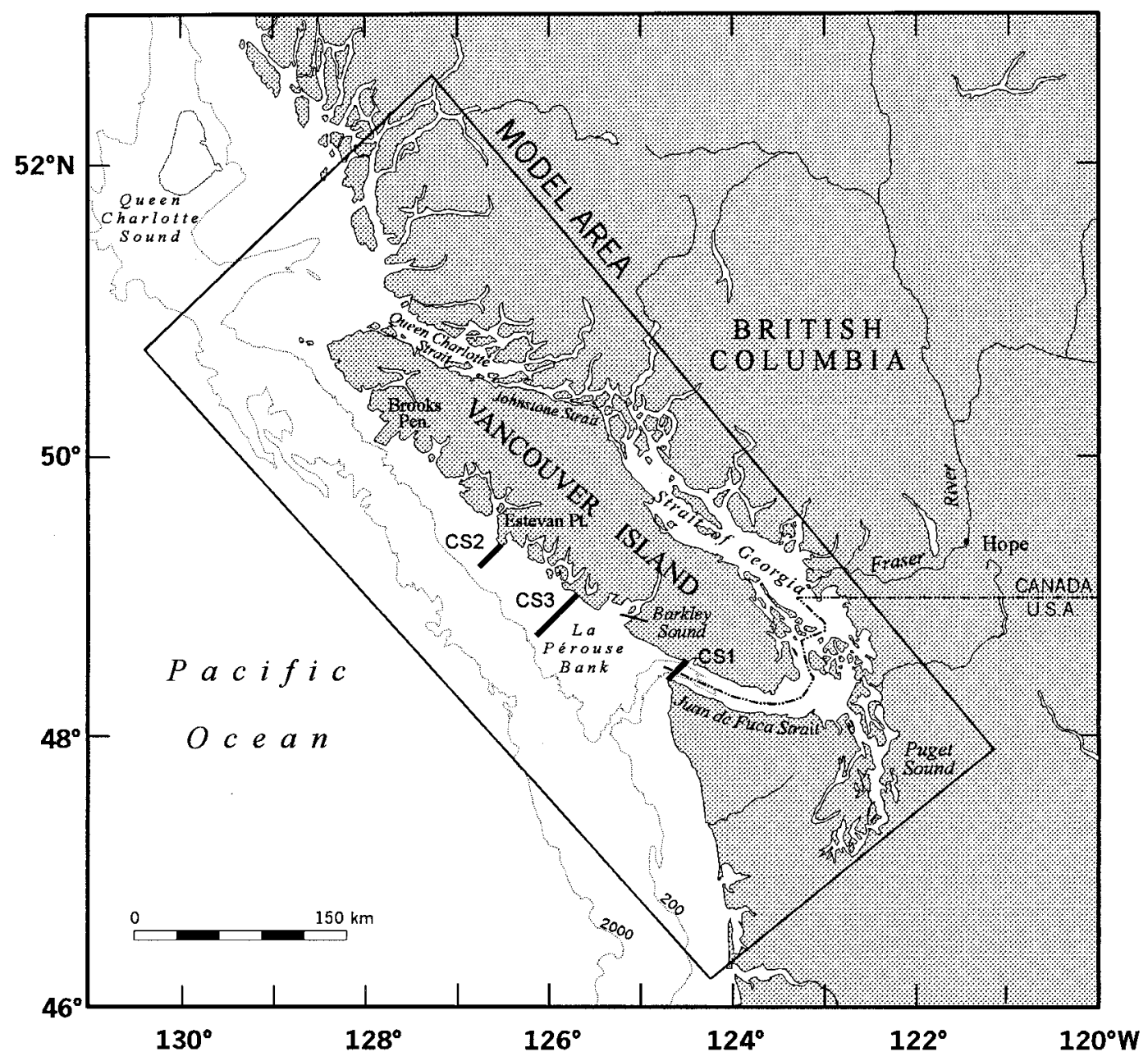

FIG. 1. The Vancouver Island coastal area and the region encompassed by the numerical model. Also included are the locations of three cross sections used in the analysis (CS1, CS2, and CS3).

ary conditions at the mouth of Juan de Fuca were specified, but this included only a barotropic outflow, not representative of the estuarine circulation. An artifact of this is that the outflow from Juan de Fuca Strait turns left on the shelf to merge with the equatorward flowing shelfbreak current, rather than forming the poleward coastal current.

In a different approach, Pal and Holloway (1996) hypothesize that bottom form stress and not the Fraser River discharge is the primary driving mechanism for the poleward flow off Vancouver Island. However, their study is unconvincing given that there is no estuarine circulation in their model and that their topographic stress parameterization leads to a bottom-intensified current, contrary to the observed vertical structure.

To examine the role of buoyancy forcing in the dynamics of the summer coastal countercurrent off Vancouver Island, the Princeton Ocean Model (POM) is applied in a series of fully prognostic numerical simulations. The objective is to show for the first time the development of the VICC due to buoyancy forcing from the Fraser River. Accordingly, the model is directly forced by the Fraser River discharge into the Strait of Georgia. The response is characterized by an estuarine circulation that establishes itself in Juan de Fuca Strait, and the formation of a distinctive coastal current over the shelf that flows poleward along the west coast of Vancouver Island. Sensitivity studies are conducted to determine the robustness of this current to initial conditions, enhanced vertical mixing, opposing winds, and grid resolution. Finally, various characteristics of the simulated coastal flow are shown to compare favorably with observations.

\section{Regional oceanography}

The region of interest comprises all of the waters surrounding Vancouver Island: the Strait of Georgia, Puget Sound, Juan de Fuca Strait, the continental shelf west of Vancouver Island, Johnstone Strait, and Queen 
Charlotte Strait (Fig. 1). The Strait of Georgia is a deep interior basin of length $200 \mathrm{~km}$. It is joined to Juan de Fuca Strait by narrow channels through a complex of islands (the Gulf and San Juan Islands). At its northern end, the Strait of Georgia is connected to the open sea through a series of constricted and shallow channels, with cross-sectional areas much smaller than those of the southern route. West of Vancouver Island, the continental shelf is wide and of complex topography to the south, becoming smoother and narrower to the north.

The main elements affecting the circulation of the study area are the winds, buoyancy forcing, tidal currents, a complex topography, and offshore oceanic processes (e.g., Thomson et al. 1989). During winter, the Aleutian low dominates the region and causes the coastal wind to blow mostly from the southeast. Conversely, during summer, the North Pacific high dominates, with weaker winds predominantly from the northwest causing summertime upwelling. The shelfbreak current, located near the $200-\mathrm{m}$ isobath, follows the prevailing coastal winds, flowing mostly to the southeast in summer and to the northwest in winter.

Freshwater runoff in the area comes from two main sources: the Fraser River entering the Strait of Georgia, forming a brackish outflow on the shelf, and a series of small rivers along the west coast of Vancouver Island. These two sources are out of phase, with maximum Fraser runoff in early summer and maximum runoff on the west coast in winter. On an annual basis, the contribution of the latter is an order of magnitude smaller than that of the Fraser. In the present work, only the Fraser River discharge is considered because of its predominance during the period of interest, summer.

In the northeast Pacific, the tide is of the mixed type with diurnal and semidiurnal tidal constituents of significant amplitude. Strong tidal streams are found in the various narrow passages leading from the Strait of Georgia to the open sea. In these passages, the level of tidal mixing may be intense. Griffin and LeBlond (1990) have shown that the properties of the surface water flowing seaward into Juan de Fuca Strait can be strongly modulated by the degree of tidal mixing in the channels. Hickey et al. (1991) used CTD and velocity data and satellite imagery to examine the pulses of surface freshwater that escape relatively unmixed during periods of neap tide. These pulses of lighter surface water are observed to travel down Juan de Fuca Strait and onto the shelf at fortnightly and monthly intervals, modulated by both mixing and wind (Hickey et al. 1991).

Since 1979, a series of field programs has provided significant amounts of data for the west coast of Vancouver Island, and the general structure of the coastal current is now better known (e.g., Thomson et al. 1989). Away from the shelf break, on the inner portion of the shelf, the VICC appears as a coherent flow originating near Barkley Sound and extending as far north as Brooks Peninsula. The core of the coastal current is located near the 50-m depth contour, rather than directly at the coast. The poleward flow of the VICC persists throughout the year, but undergoes a seasonal modulation, with greatest magnitudes of about $50 \mathrm{~cm} \mathrm{~s}^{-1}$ observed during winter months, when it flows in the same direction as the southeasterly winds. The coastal flow is surface-intensified in winter, but, in summer, under the influence of the opposing seasonal wind, it has a subsurface maximum. The VICC can be clearly identified in summer as a narrow current, flowing against the mean seasonal winds, with a subsurface maximum of about $10 \mathrm{~cm} \mathrm{~s}^{-1}$ at a depth of about $20 \mathrm{~m}$.

Another recurrent feature of the shelf circulation is a counterclockwise eddylike feature that forms west of the mouth of Juan de Fuca Strait, during the summer months. The eddy is located above a narrow canyon that cuts across the continental shelf, and observations show that this canyon is a conduit for upwelling water during summer (Freeland and Denman 1982).

\section{The numerical model}

This study uses a three-dimensional hydrodynamic model initially developed by Blumberg and Mellor (1987). The present version of the model includes modifications made by Oey and Chen (1992) and Oey (1996). The model solves the time-dependent, primitive equations of motion in a bottom-following sigma-coordinate system. It contains a free surface formulation and complete thermodynamics, with an embedded level2.5 turbulence closure submodel to provide vertical mixing coefficients (Mellor and Yamada 1982). A staggered $\mathrm{C}$-grid differencing scheme is adopted with explicit time stepping, except for vertical diffusion terms which are treated implicitly. The model uses a mode-splitting method with a short two-dimensional external mode time step and a longer three-dimensional internal time step, based on the external and internal CFL conditions, respectively.

The horizontal viscosity and diffusivity are parameterized by the Smagorinsky formula

$$
A_{M}=c(\Delta s)^{2} \frac{1}{2}\left|\nabla \mathbf{V}+(\boldsymbol{\nabla} \mathbf{V})^{\mathrm{T}}\right|,
$$

where $A_{M}$ is the horizontal viscosity and diffusivity coefficient, $\Delta s$ the grid size, and $\mathbf{V}$ the horizontal velocity vector. The nondimensional constant $c$ is set to a value of 0.1 throughout the study, which is sufficient to maintain a smooth solution while minimizing the lateral mixing.

\section{a. Model domain}

The model domain consists of a $300 \mathrm{~km}$ by $678 \mathrm{~km}$ area including the entire coastal system surrounding Vancouver Island (Fig. 1). This contrasts with previous numerical studies of the area, which were limited either to the west coast (e.g., Pal and Holloway 1996) or to 
the interior waters (e.g., Stronach et al. 1993). Including all the coastal waters enables us to force the model directly with river discharge at the mouth of the Fraser River in the Strait of Georgia and permits the establishment of an estuarine circulation as the plume reaches the shelf.

The horizontal grid spacing is uniform with a Lambert conformal conic projection used to map the Cartesian coordinate of the model onto geographic coordinates. The grid resolution is $3 \mathrm{~km}$ for all experiments, except for one case where it is increased to $2 \mathrm{~km}$ to check for resolution effects. Depths at each grid point were determined by averaging topographic values from a highresolution dataset over a circular area with radius given by the model grid spacing. This approach introduces some finer topographic scales in the $2-\mathrm{km}$ grid. The coastline is approximated as realistically as possible for a given grid resolution. A clockwise rotation of $40^{\circ}$ from true north is applied to align approximately the local coastline with the $y$ coordinate of the model. Thus, in the following, the $x$ and $y$ coordinates are referred to as the cross-shore and alongshore directions, respectively. The Coriolis parameter is set to a constant value, $f=$ $1.1 \times 10^{-4} \mathrm{~s}^{-1}$, appropriate to a latitude of $49^{\circ} \mathrm{N}$. For all but one experiment, there are 15 sigma levels in the vertical, with finer resolution near the surface and bottom. In one case, the vertical resolution is increased to 31 sigma levels.

\section{b. Initial and boundary conditions}

In the summer, the main source of freshwater in the area is the Fraser River, which drains the largest watershed in British Columbia. Its discharge peaks in early summer from snowmelt to reach rapidly a maximum freshet discharge that may be, in some years, as great as $15000 \mathrm{~m}^{3} \mathrm{~s}^{-1}$ (Fig. 2a). The freshwater enters the Strait of Georgia through two channels (see Fig. 1), with about $87 \%$ of the total discharge in the northern arm. Accordingly, the river is modeled as two neighboring point sources of freshwater. The freshwater is introduced in the continuity equation as a surface volume flux of zero salinity water (Oey 1996). Daily discharge rates are taken as the daily mean values of Fig. 2a, computed from hydrological data collected over the last 84 years at Hope, British Columbia, located about $150 \mathrm{~km}$ upstream of the river mouth (see Fig. 1). This is a conservative estimate of the total freshwater discharge into the interior basins because it likely underestimates the total Fraser discharge at the mouth of the river and because the smaller contributions from secondary tributaries are not included (LeBlond et al. 1983).

Initially, the ocean is quiescent and homogeneous with salinity $S=33.8 \mathrm{psu}$ and temperature $T=8^{\circ} \mathrm{C}$. However, for two experiments, the initial state is prescribed as the end state of an initialization run, thus allowing for the presence of a freshwater plume close to the coast. For simplicity, the temperature of the fresh-
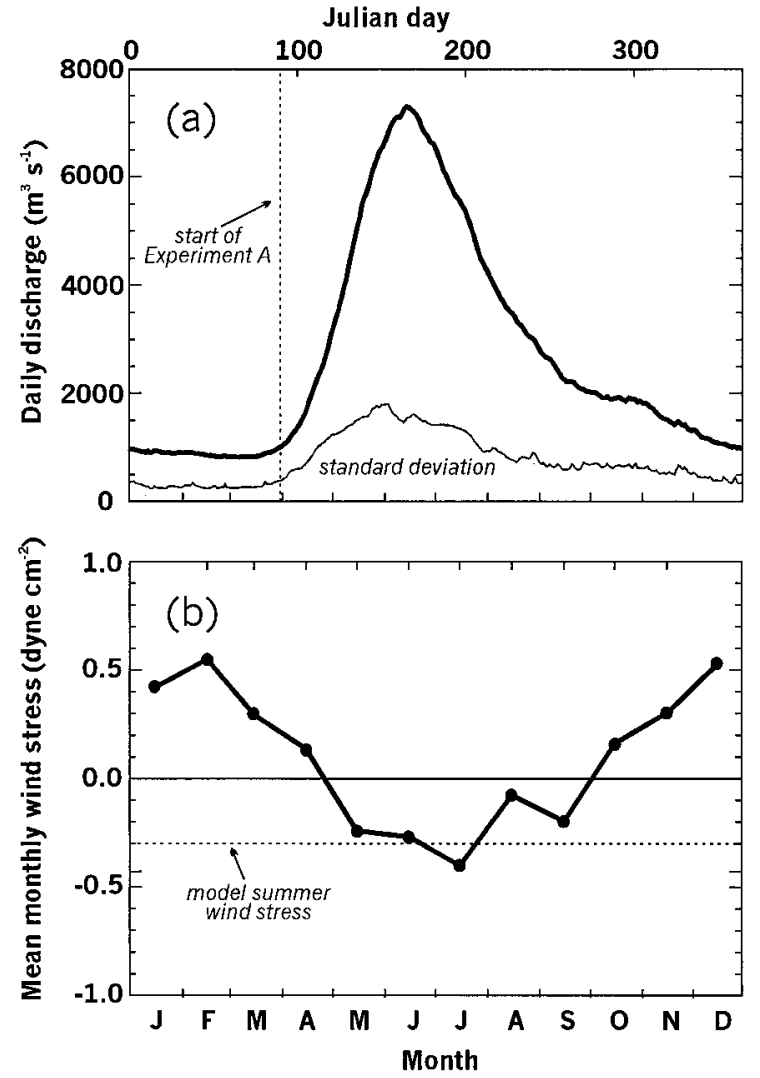

FIG. 2. (a) Mean daily Fraser river discharge and its standard deviation. The mean values are computed from hydrological data measured at Hope, British Columbia, over the period 1912-95. (b) Mean monthly alongshore wind stress from a weather buoy on La Pérouse Bank.

water discharge is also taken as $T=8^{\circ} \mathrm{C}$. Consequently, for all experiments, since temperature is constant, the temperature equation is not solved and the density is controlled by salinity only.

For one of the experiments, a spatially uniform alongshore wind stress is used to force the model in addition to the freshwater input. Figure $2 b$ gives mean monthly alongshore wind stress values characteristic of the area. The wind stress was estimated from anemometer data collected by a nearshore weather buoy located on La Pérouse Bank between 1989 and 1994. The period of interest here is summer when a mean wind blows with moderate intensity to the southeast, opposite to the coastal current. Thus, in the windforced case, a constant uniform wind stress with a magnitude of 0.3 dyn $\mathrm{cm}^{-2}$ directed to the southeast (along the $y$ axis) is included.

Open boundary conditions, similar to those of Oey and Chen (1992), are applied at the northern and western edges of the model domain. These boundaries are remote from the regions of interest and there are no prescribed inflows or outflows. Although the open boundary conditions have little or no influence on the nu- 
TABLE 1. Numerical experiments.

\begin{tabular}{|c|c|c|c|c|c|}
\hline Experiment & Initial state & $\begin{array}{c}\text { Freshwater } \\
\left(\mathrm{m}^{3} \mathrm{~s}^{-1}\right)\end{array}$ & $\begin{array}{c}\text { Wind } \\
\left(\mathrm{dyn} \mathrm{cm}^{-2}\right)\end{array}$ & $\begin{array}{l}\text { Duration } \\
\text { (days) }\end{array}$ & Comment \\
\hline A & Rest & Freshet & 0 & 220 & Basic expt \\
\hline B & Rest & 2700 & 0 & 210 & Initialization \\
\hline $\mathrm{C}$ & End of B & Freshet & 0 & 120 & \\
\hline $\mathrm{D}$ & End of B & Freshet & -0.3 & 150 & \\
\hline $\mathrm{E}$ & Rest & 2700 & 0 & 210 & Extra vertical mixing \\
\hline $\mathrm{F}$ & Rest & 2700 & 0 & 210 & 2-km horizontal grid \\
\hline G & Rest & 2700 & 0 & 210 & 31 vertical levels \\
\hline
\end{tabular}

merical solutions, for completeness we note that the surface elevation and the normal component of the external velocity are time-stepped with a radiation condition based on the gravity wave speed (see Oey and Chen 1992). An Orlanski radiation condition is applied for the normal component of the internal velocity along the open boundaries. The salinity and the tangential component of the external velocity are advanced using an upwind advection condition. Finally, a free-slip condition is applied for the tangential component of the internal velocity.

\section{Description of experiments}

The various experiments mentioned in this study are summarized in Table 1. The second column of the table describes the initial state of the model at the beginning of each experiment. This is either a state of rest (uniform and quiescent ocean) or end of B (the final state of expt B). In the third column, freshet refers to a time-varying discharge from the Fraser River corresponding to the early summer freshet period (see Fig. 2a).

For experiment A, the basic case, the model is forced by a time-varying freshwater input into an initially homogeneous, quiescent ocean. Additional runs are conducted to examine sensitivity to initial conditions, wind forcing, localized mixing within the estuary, and grid resolution. An initialization run is performed where the system, initially at rest, is forced by a constant river discharge (expt B). The flow rate in this case is 2700 $\mathrm{m}^{3} \mathrm{~s}^{-1}$, the mean annual daily discharge rate from the Fraser River. The long integration period of 210 days for this calculation allows the coastal current to approach a quasi-steady state. The end state of run B is used as the starting point for experiments $\mathrm{C}$ and $\mathrm{D}$, where the model is either forced by buoyancy only (C) or by buoyancy and wind (D), through the freshet period.

Since tides are not included in the model, vertical mixing over the shallow sills within the estuary may be underestimated. To examine the possible effects of locally enhanced mixing of the plume on the buoyancy forcing of the coastal current, the initialization run is repeated in experiment $\mathrm{E}$, with high vertical mixing in- troduced over a shallow sill located near the head of Juan de Fuca Strait.

Two experiments were conducted to examine whether the results are sensitive to variations in resolution. The initialization run (B) was repeated on a finer $2-\mathrm{km}$ grid in experiment $\mathrm{F}$, and with 31 sigma levels in experiment G. These cases examine mostly the sensitivity to a better resolution of topography and salinity fronts (in F), and of the bottom boundary layer (in G). It is well known that the discretization error associated with the baroclinic pressure gradient in sigma coordinates can lead to the generation of spurious flows. However, this truncation error decreases as the square of the grid size, and the basic resolution of $3 \mathrm{~km}$ is such that this should not cause a problem (Mellor et al. 1994).

The results of experiments $F$ and $\mathrm{G}$ indicate relatively little sensitivity to grid resolution. The structure of the modeled coastal current is similar to that of experiment B, with only small quantitative differences. The most significant change occurs in the 2-km case where the salinity front is somewhat more sharply defined, leading to a slightly more rapid advance of the density intrusion (described below). Because of their similarity to experiment $\mathrm{B}$, further discussion of cases $\mathrm{F}$ and $\mathrm{G}$ is omitted.

\section{a. Basic case}

The integration of the basic calculation starts in the spring on day 90 of the yearly discharge cycle of Fig. $2 \mathrm{a}$, just before the rapid increase of river outflow associated with the freshet. It is terminated near the end of the year, when the winter river flow is very low (day 310). Figure 3 gives contours of surface salinity at four times during experiment $\mathrm{A}$ and shows the progression of the buoyant plume. In the first few days of the integration, a freshwater plume forms in the vicinity of the river mouth and quickly reaches the islands westward of the river [Figs. 3a (after 1 day) and 3b (after 7 days)]. The plume gradually spreads over the entire Strait of Georgia, making its way seaward through the Gulf and San Juan Islands and Juan de Fuca Strait to the south, and through the narrow northern passages (Fig. 3c). Juan de Fuca Strait is wide enough for the 

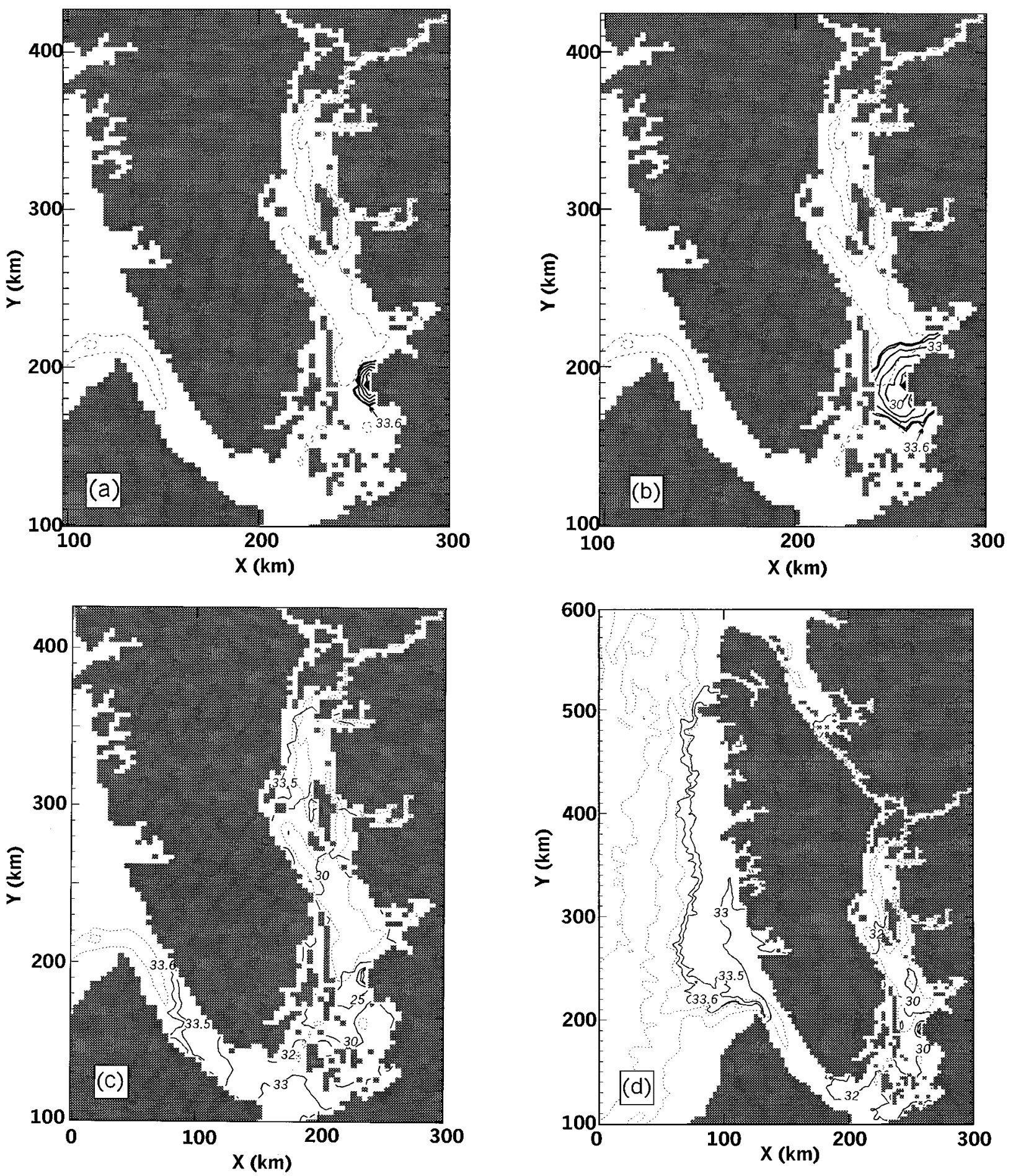

FIG. 3. Contours of surface salinity from experiment A (basic case) after 1 (a), 7 (b), 60 (c), and 160 (d) days of integration. The salinity contours are for values of 10,15, 20, 25, 30, 32, 33, 33.5, and 33.6 psu. Depth contours (dotted lines) are for the 200-m, 1000-m, and 2000-m isobaths.

Coriolis force to deflect the freshwater to the north coast of the channel. As expected, given the limited cross section of the constricted passages of the northern route, the primary seaward path followed by the plume is through Juan de Fuca Strait. The southern branch of the simulated plume reaches the mouth of Juan de Fuca Strait after about 60 days, while the northern extent of the plume has reached only the entrance of Johnstone 


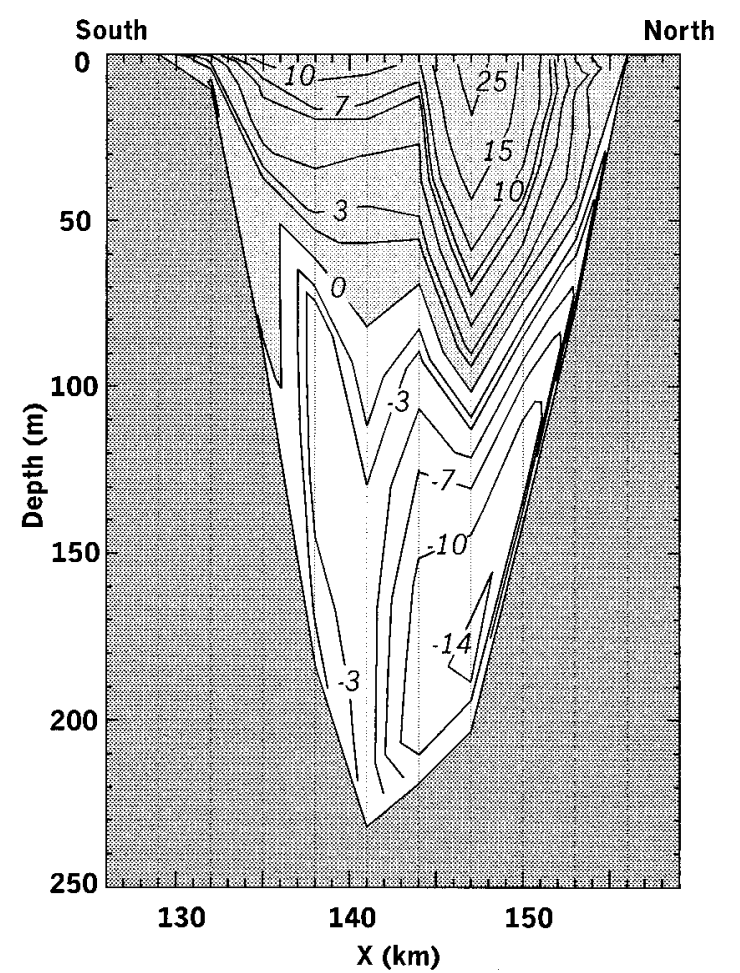

FIG. 4. Velocity normal to a $x-z$ cross section located at the mouth of Juan de Fuca Strait (CS1), after 120 days in experiment A (basic case). Velocities are in $\mathrm{cm} \mathrm{s}^{-1}$ with positive values for flow out of the Strait.

Strait by this time (Fig. 3c). Once it flows onto the shelf, the freshwater turns to form a right-bounded density current along the coast, which eventually reaches the model northern boundary near the end of the calculation (Fig. 3d).

When the plume spreads over the continental shelf, an estuarine circulation has formed in Juan de Fuca Strait with typical fresh outflow near the surface and saltier return flow at depth. Alongshore velocities are contoured in Fig. 4 along a vertical cross section located across the mouth of Juan de Fuca Strait (see CS1 on Fig. 1), after 120 days in experiment A. Positive values are for velocities directed outside the strait. Once the estuarine circulation is well established, its strength varies as the freshwater discharge changes, but the cross-sectional distribution of the flow is essentially unchanged, with the zero contour reaching a maximum depth of about $100 \mathrm{~m}$. Both the inflow into the strait and the outflow are concentrated on the northern side of the channel, and maximum velocities of 30 and 15 $\mathrm{cm} \mathrm{s}^{-1}$ for the outflow and inflow, respectively, are obtained after about 120 days of integration.

Associated with the presence of a plume on the shelf is the upward displacement of the sea surface. As the freshwater enters the open ocean, a bulge, or mound, typically forms near the mouth of the estuary (e.g., Chao and Boicourt 1986). Emanating from this region is the right-bounded coastal current. The surface elevation field on the shelf is given after 60 days in Fig. 5a. At that time, the head of the density intrusion is approaching the western end of Juan de Fuca Strait. The sea surface elevation shows an upward displacement on the north side near the mouth of Juan de Fuca Strait, with a pronounced alongshore gradient behind the head of the density intrusion. In addition, a weaker downward sea surface slope extends upstream of the density intrusion, as far as Brooks Peninsula. The surface elevation field is presented in Fig. $5 \mathrm{~b}$ for a later time when the density intrusion has reached the northern tip of the island (after 160 days). The downward slope is now more uniformly distributed along the island, with a total alongshore displacement of about $3 \mathrm{~cm}$ down from the mouth of the estuary.

As the plume develops on the shelf, the coastal current begins to form, flowing northwestward along the coast, and eventually reaching the northern end of Vancouver Island. Surface current vectors are plotted in Fig. 6, averaged over a 5-day period, after 160 days of integration. The coastal current is seen to originate near the mouth of the strait. At first, it flows up the coast in a somewhat confused path off Barkley Sound, where the shelf is wide and the topography complex. North of this area, the current becomes better defined as the shelf narrows and becomes smoother. The current vectors generally follow depth contours and the intensity of the coastal current gradually decreases away from its source, except for locally increased velocity in certain areas where the shelf narrows near promontories, particularly off Estevan Point and Brooks Peninsula.

Also evident in Fig. 6 is the return flow along the canyon entering Juan de Fuca, which brings shelfbreak water up into the strait. This topographically steered upwelling extends through most of the water column. It appears to be driven by the estuarine circulation near the mouth of the strait and can be associated with similar upwelling motion obtained by Chao and Boicourt (1986).

The vertical structure of the current is examined through contours of alongshore velocities on a crossshore vertical section (CS2 on Fig. 1) off Estevan Point. Early in experiment A (after 60 days), the density intrusion has not yet reached this location, and the coastal current is locally barotropic, with a width of about 20 $\mathrm{km}$ (Fig 7a). Maximum values of $10 \mathrm{~cm} \mathrm{~s}^{-1}$ are found at about $10 \mathrm{~km}$ from the coast, above the $50-\mathrm{m}$ isobath. As indicated in Fig. 6, the core of the current is located farther away from the coast (about $20 \mathrm{~km}$ ) along most of the island, but it approaches the shore near promontories such as Estevan Point. At a later time in the calculation (after 160 days), the light water has spread past Estevan point, and the local alongshore current is now stronger and baroclinic, with a surface-intensified structure (Fig. 7b). The coastal current has the general 


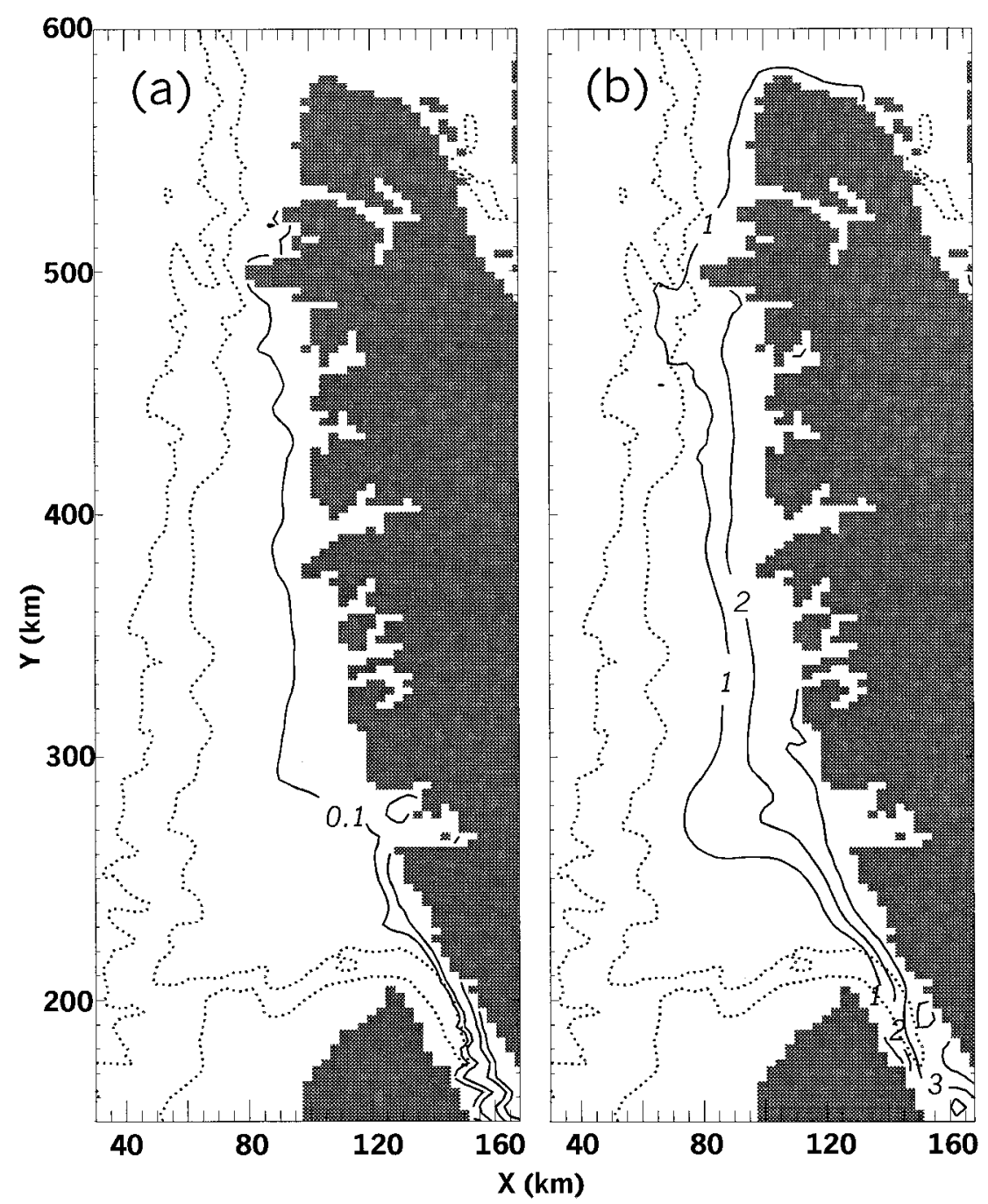

FIG. 5. Sea surface elevation in $\mathrm{cm}$ after 60 (a) and 160 (b) days of experiment A (basic case). Note the difference in contour labels.

characteristics of a buoyancy-driven density intrusion (e.g., Chao 1987).

To better understand the dynamical processes acting over the shelf and driving the coastal current, the various terms of the vertically integrated, alongshore momentum equation are examined. The momentum equation in the alongshore $(y)$ direction takes the form (e.g., Blumberg and Mellor 1987):

$$
\frac{\partial \bar{V} D}{\partial t}+\frac{\partial \overline{U V} D}{\partial x}+\frac{\partial \overline{V^{2}} D}{\partial y}+f \bar{U} D+g D \frac{\partial \eta}{\partial y}-\overline{F_{y}}=\tau_{s}^{y}-\tau_{b}^{y}-\frac{g D}{\rho_{0}} \int_{-1}^{0} \int_{\sigma}^{0}\left(D \frac{\partial \rho}{\partial y}-\frac{\partial D}{\partial y} \sigma^{\prime} \frac{\partial \rho}{\partial \sigma^{\prime}}\right) d \sigma^{\prime} d \sigma
$$

where $D=H+\eta$ is the total water depth, $(U, V)$ the horizontal components of velocity, $\eta$ the surface elevation, and $\rho$ the perturbation density. The overbar denotes a vertically averaged variable and $\sigma=(z-$ $\eta) / D$ is the bottom-following sigma coordinate. The components of the wind and bottom stress in the $y$ direction are denoted $\tau_{s}^{y}$ and $\tau_{b}^{y}$, respectively. The quantity $F_{y}$ represents the $y$ component of the horizontal momentum diffusion operator. The terms of Eq. (2) represent (from left to right) local acceleration, $x$ and 


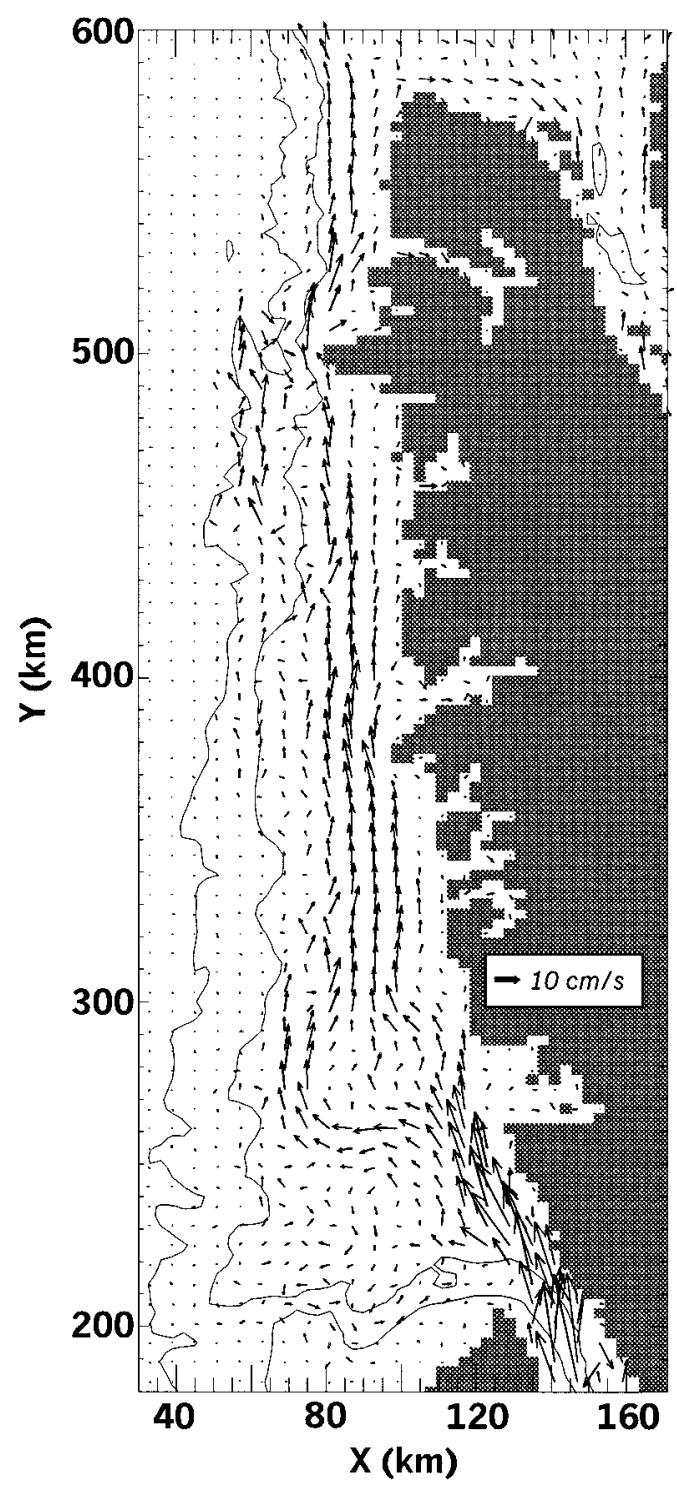

FIG. 6. Mean surface velocity vectors averaged over a 5-day period, after 160 days of experiment A (basic case). Only every second vector in each coordinate direction is shown.

$y$ advection of alongshore momentum, Coriolis acceleration, barotropic pressure gradient, horizontal diffusion, surface and bottom stresses, and finally baroclinic pressure gradient.

Because the coastal current is not perfectly aligned with the chosen alongshore direction $y$, the momentum balance is dominated by the geostrophic terms: the Coriolis force and the two pressure gradients. However, the important driving force for the coastal current is the small imbalance or residual between these three terms that develops near the coast. In Fig. 8a, the various alongshore momentum terms, measured after 60 days, are given along a vertical section located about $50 \mathrm{~km}$ upstream from Estevan Point (CS3 of Fig. 1), where the coastal current is fairly closely aligned with the along- shore direction. As seen in the depth-averaged current vectors, the section cuts across the developing coastal current. At this early stage, the density intrusion has not yet reached this location and the current is driven by the barotropic pressure gradient caused by the sea surface sloping down from the hydraulic head that forms at the mouth of Juan de Fuca Strait (see Fig. 5a). Bottom friction provides some resistance to the current, but in the early stages of development, the coastal flow is rapidly gaining strength, with a relatively large local acceleration term. The advection and diffusion terms play only a minor role in the balance. At a later time in this calculation, the light water has advanced up the coast, introducing into the momentum balance a baroclinic pressure gradient that opposes the coastal current. But this counter effect of the plume is more than compensated by a concomitant increase in the local barotropic pressure gradient (see Fig. 5b), so that the dominant alongshore momentum balance remains between the barotropic pressure gradient and bottom friction.

In experiment $\mathrm{A}$, the Fraser River discharge varies continuously as it goes through the annual cycle of Fig. $2 \mathrm{a}$. From the start of the experiment at day 90 of this cycle, the freshwater input rapidly increases from a low early spring value of about $1000 \mathrm{~m}^{3} \mathrm{~s}^{-1}$ to reach a maximum freshet discharge of more than $7000 \mathrm{~m}^{3} \mathrm{~s}^{-1} 75$ days later. The modeled ocean, originally homogeneous and quiescent, continuously adjusts to the rapidly varying buoyancy forcing. To describe the evolution of the coastal current, a time series is given in Fig. 9 of the alongshore volume transport through the cross-shore vertical section CS2. The volume of water advected poleward by the coastal current follows the strength of the buoyancy forcing, reaching a maximum value of about $10^{5} \mathrm{~m}^{3} \mathrm{~s}^{-1}$, over an order of magnitude larger than the volume of freshwater discharge forcing the model.

The maximum in volume transport at Estevan Point occurs about two months after the maximum river freshet discharge (see Fig. 9). This relatively long delay is mostly determined by the time required for the light water to reach this location. The speed of advance of the density intrusion has been estimated by measuring the alongshore penetration of the 33.7 psu salinity contour. This yields a mean value of $3 \mathrm{~cm} \mathrm{~s}^{-1}$, consistent with previous estimates of intrusion speeds on a shelf obtained by Chao and Boicourt (1986) and Chao (1987).

\section{b. Additional experiments}

\section{1) INITIALIZATION RUN}

In the basic experiment, the homogeneous conditions prevalent at the onset of the freshet period may not lead to a realistic time evolution of the coastal current. In the spring, when the Fraser River discharge is about to amplify, there is some freshwater influence present in the coastal system due to winter runoff. To examine the 

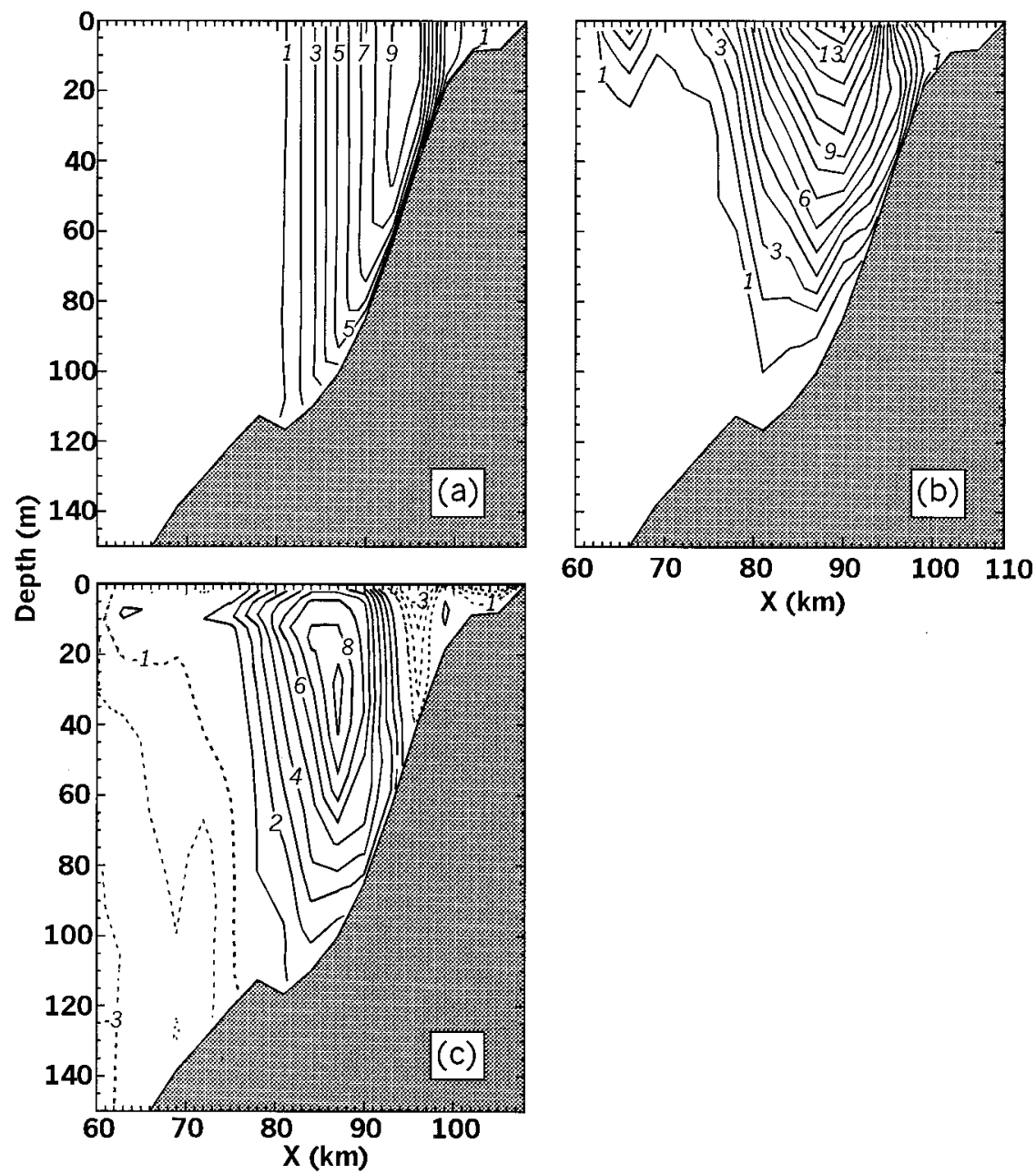

FIG. 7. Contours of alongshore velocity (in $\mathrm{cm} \mathrm{s}^{-1}$ ) on a cross-shore vertical section off Estevan Point (CS2). The velocity fields are means over a 5-day period, after 100 (a) and 160 (b) days of experiment A (basic case) and after 75 days of experiment D (wind-forced case) (c). Discussion of (a) and (b) is given in section $4 a$, and of (c) in section $4 b(3)$.

dependence of the time evolution of the coastal current on initial conditions, an initialization run is first performed (expt B). In this experiment, the Fraser River flow is kept constant at a moderate value of $2700 \mathrm{~m}^{3}$ $\mathrm{s}^{-1}$, the annual-mean daily discharge. The model is run for 210 days, long enough for the coastal ocean to approach a quasi-steady state. Under the influence of the steady forcing, the coastal current develops and the alongshore transport off Estevan Point stabilizes to approximately $8 \times 10^{4} \mathrm{~m}^{3} \mathrm{~s}^{-1}$. In Fig. $8 \mathrm{~b}$, the various terms of the alongshore momentum balance are given for the same cross-shore section (CS3) as in Fig. 8a, computed near the end of the initialization run. By this time, the coastal current has attained a nearly steady state and the local acceleration term is small. As in the basic case, after passage of the plume, the flow is baroclinic and the baroclinic pressure gradient term is nonzero. However, the coastal current is again driven mostly by the alongshore barotropic pressure gradient, with bottom stresses largely balancing the residual sum of the geostrophic terms (the Coriolis and the barotropic and baroclinic pressure gradient terms).

Near the end of the initialization run, a quasi-steady plume is present at the mouth of the Fraser River, and a clear salinity contrast now exists between the interior waters, the Straits of Georgia and Juan de Fuca, and the water on the shelf. Examination of the salinity field indicates a density front in the vicinity of the Victoria sill, located across the head of Juan de Fuca Strait. These features of the density field are consistent with the springtime measurements of Crean and Ages (1971) taken along the Straits of Georgia and Juan de Fuca. Hence, the end state of experiment B is used as an initial condition for experiments $\mathrm{E}$ and $\mathrm{F}$, in an attempt to identify its effects on the evolution of the coastal current during the freshet period. 


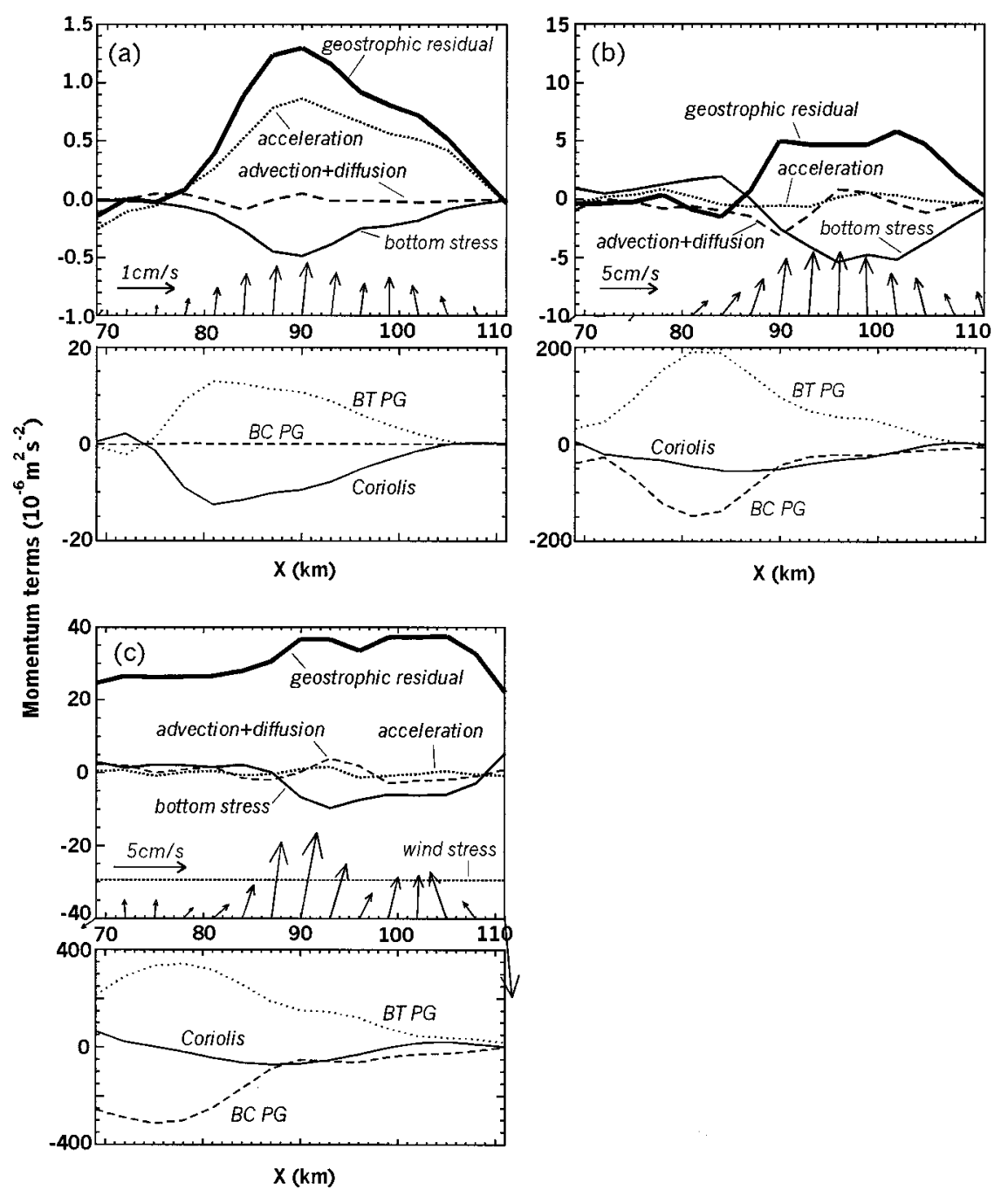

FIG. 8. Alongshore momentum balance on a cross-shore section located about $50 \mathrm{~km}$ south of Estevan Point (CS3). The depth-averaged velocity vectors along the section are also given. The balance is given after 60 days in experiment A (basic case) (a), at the end of experiment B (initialization run) (b), and of experiment D (wind forced case) (c). The geostrophic residual is the sum of the Coriolis term, the barotropic pressure gradient (BT PG), and the baroclinic pressure gradient (BC PG). The sign convention is such that the local acceleration is equal to the sum of the other terms.

\section{2) INITIALIZED FRESHET}

Experiment $\mathrm{C}$ starts from the final state of experiment $\mathrm{B}$, with the estuarine circulation and the coastal current already established. The freshwater influx increases from the initial rate of $2700 \mathrm{~m}^{3} \mathrm{~s}^{-1}$ on day 118 to the maximum freshet discharge, following the seasonal cycle of Fig. 2a. As the buoyancy forcing augments, the coastal current strengthens to reach a maximum transport at CS2 of $9.7 \times 10^{4} \mathrm{~m}^{3} \mathrm{~s}^{-1}$ after 60 days (Fig. 9). The value of the maximum alongshore transport by the coastal current is comparable to the one obtained in the basic case (expt A) but now this maximum occurs only 11 days after the river freshet. The shorter response time of the coastal transport to the river discharge rate is now of the order of the advection timescale set by the mean current, with an average speed of about $15 \mathrm{~cm} \mathrm{~s}^{-1}$. This result indicates that, by letting the system first adjust to a low background freshwater input, the coastal response to a change in river discharge is much more rapid.

\section{3) COUnTER winds}

In the previous experiments, the Fraser discharge was demonstrated to be capable of driving a clearly defined, poleward current along the coast of Vancouver Island. Such a current is known to exist throughout the year, including the summer period when the local seasonal wind blows in an opposing sense. Can the modeled 


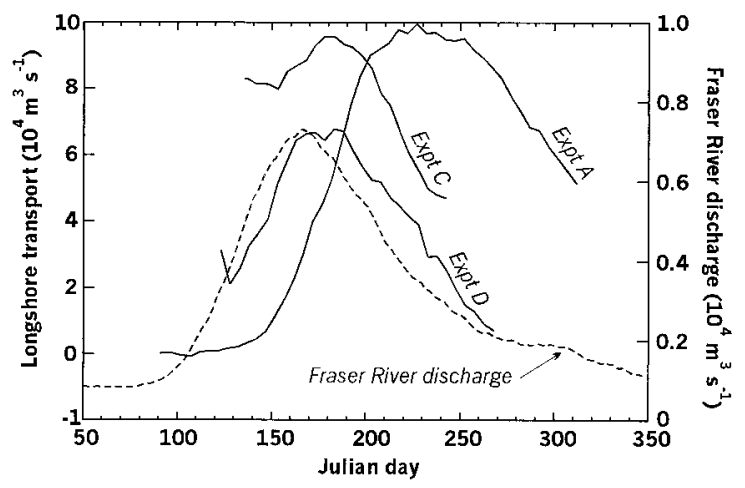

FIG. 9. Alongshore volume transport normal to the vertical cross section CS2 for experiments A (basic case), C (initialized run), and $\mathrm{D}$ (wind-forced case). The Fraser River discharge at Hope is also given for comparison.

coastal current survive such an opposing wind, and if so, how does this change its characteristics? To examine these questions, the previous experiment $(\mathrm{C})$ is repeated, but this time including wind forcing. The wind stress

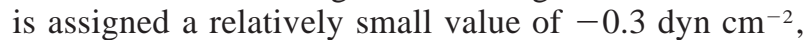
representative of mean summer conditions (see Fig. 2b). The spatially uniform wind stress is applied over the entire domain (including the inner basins), in the $y$ direction, blowing from the northwest. For this simulation

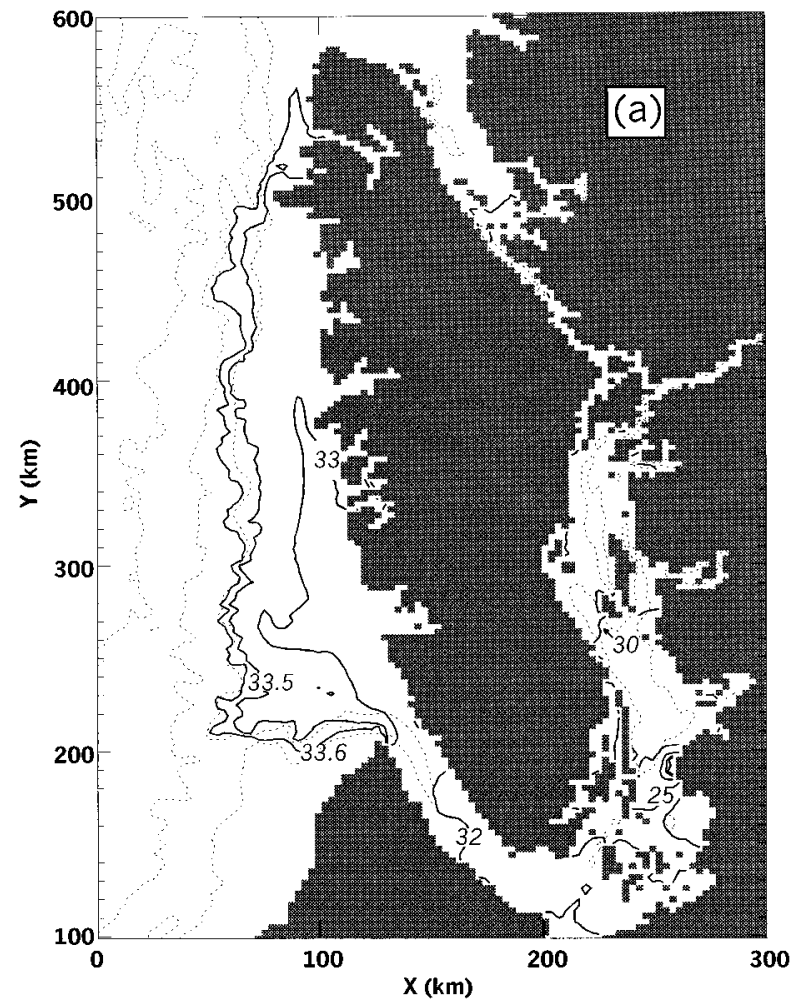

(expt D), the model is run for 150 days, extending well past the peak of the river freshet.

The first evidence of the effect of the wind stress is given by the surface salinity contours over the shelf. Comparison of the results from the wind-forced case (Fig. 10b) with those of experiment C (Fig. 10a) indicates that the wind pushes the freshwater near the surface offshore as it reaches the continental shelf. For example, in Fig. 10b, the core of the plume now extends across La Pérouse Bank to the 200-m depth contour, in an offshore-directed tongue originating at the estuary mouth. Also, along the west coast of Vancouver Island, the main axis of the plume is displaced offshore by the wind. A similar effect of an upwelling-favorable wind stress on a freshwater plume was obtained by Kourafalou et al. (1996) for the South Atlantic Bight region.

The alongshore volume transport along the west coast obtained in experiment D is given in Fig. 9. At first, the wind stress rapidly slows down the coastal current but, as the river discharge increases, the current strengthens to reach a maximum transport at about the same time as in the previous calculation that did not include wind forcing (expt C). However, the alongshore transport by the coastal current is now reduced to about $60 \%$ of its previous value. After the freshet, the current gradually weakens as the buoyancy forcing decreases. The effectiveness of the opposing wind in slowing down

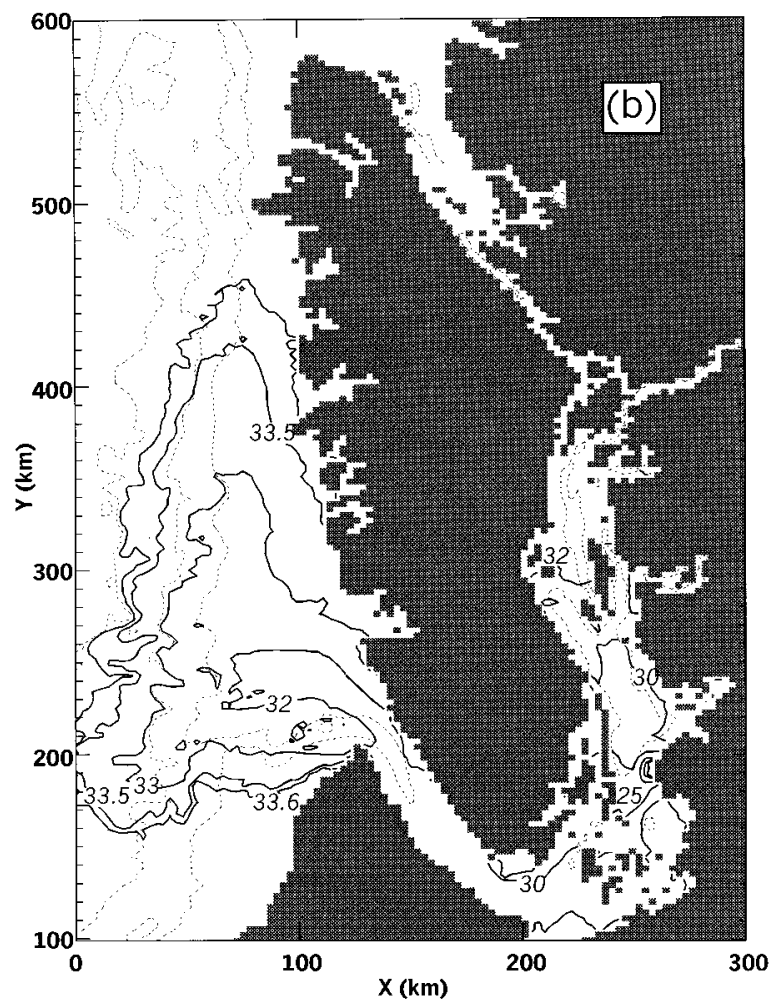

FIG. 10. Contours of surface salinity after 100 days of integration for experiment C (initialized run) (a) and experiment D (wind-forced case) (b). The salinity and depth contours are as in Fig. 3. 
the coastal current is clearly evident, but, at all times, the volume transport off Estevan Point remains positive (poleward). In fact, the results show that the integrity of the buoyancy-driven current is preserved over the entire integration period as far as Brooks Peninsula. The simulated current does indeed survive along most of Vancouver Island against the opposing seasonal wind, through the entire summer season.

In addition to reducing the magnitude of the current, the wind stress also modifies its spatial structure. Contours of the alongshore velocity on the cross-section CS2 are presented in Fig. 7c, 75 days after the start of experiment D. The core of the current has shifted from the surface down to a depth of about $30 \mathrm{~m}$, below the wind-driven Ekman layer. It has also been slightly displaced offshore, following the movement of the surface plume. Another interesting difference from the case without wind is the presence of a weak inshore current flowing in the direction of the wind, separating the counter current from the coast.

An alongshore momentum balance analysis is given in Fig. 8c, for experiment D near the time of maximum transport by the coastal current. Within the coastal current, the acceleration and the advection-diffusion terms are relatively small. Again, the coastal current is forced by a relatively strong residual barotropic pressure gradient. The momentum balance is now between the wind and bottom stresses opposing the flow, and the residual sum of the geostrophic terms (Coriolis force and pressure gradients).

\section{4) ENHANCED VERTICAL MiXING}

As mentioned in section 2, flows over shallow sills in the interior basins, including those due to tides, are known to be efficient in mixing the freshwater plume on its way to the shelf. The possible effects of enhanced vertical mixing of the plume within the estuary on the coastal current are investigated in experiment $\mathrm{E}$, where experiment $\mathrm{B}$, the initialization run, is repeated with the vertical coefficients of viscosity and diffusion set to a large value $\left(0.05 \mathrm{~m}^{2} \mathrm{~s}^{-1}\right)$ over a shallow sill that spans the eastern end of Juan de Fuca Strait (the Victoria sill). Hydrographic transects along the strait indicate that the main density front within the estuary is located over this sill (Crean and Ages 1971). By comparison, the vertical mixing coefficients in experiment $B$ have an average value of about $0.005 \mathrm{~m}^{2} \mathrm{~s}^{-1}$ in the vicinity of the plume, within the interior basin.

Results from this case show that, as the modeled freshwater plume reaches the sill area, the extra mixing is effective at mixing the plume vertically, resulting in a more horizontally stratified plume in Juan de Fuca Strait. Furthermore, compared to the first initialization run (B), the offshore progression of the surface plume is slowed considerably, in agreement with Chao and Boicourt (1986), who found that increased vertical mixing was efficient in retarding the progression of the den- sity intrusion. However, aside from the time delay, the evolution of the coastal current itself is almost unchanged compared to the case without enhanced mixing. A maximum alongshore volume transport is reached with an amplitude reduced by only $5 \%$ compared to experiment B. Although the properties of the surface waters in Juan de Fuca Strait are changed considerably, the general characteristics of the coastal current are practically unchanged. This result suggests that the buoyancy forcing responsible for the coastal current is relatively insensitive to details on mixing of the river plume within the estuary. The analysis of the alongshore momentum balance presented above demonstrated that the coastal current is mostly driven by an alongshore barotropic pressure gradient formed by the outflow of freshwater forming a bulge at the mouth of the estuary. It is not surprising then to see that the strength of this forcing does not depend strongly on the baroclinic structure of the plume within the estuary.

\section{Comparison with data}

In section 4, results from a series of numerical experiments were used to describe some general characteristics of a buoyancy-driven coastal current similar to the Vancouver Island coastal current. We now present a more quantitative comparison of the modeled current with field data. Results from experiment D are used in the comparison since the inclusion of wind forcing makes it the most realistically configured case.

At the source of the coastal current is the estuarine circulation established in Juan de Fuca Strait by the Fraser River outflow. In 1984, an array of current meters was deployed at the mouth of the strait as part of an extensive field survey of the local coastal circulation (Hickey et al. 1991). In Fig. 11, the mean summer alongshore velocity $(v)$ is given for a section across the mouth of the strait, which corresponds closely to the section CS1 (see Fig. 1). Figure 11a gives the current measured in summer 1984, and Fig. 11b the velocities from experiment D. The model currents are averages over a 30day period centered around the time of maximum alongshore transport of the coastal current. In both cases, the surface outflow extends to a depth ranging from 50 to $100 \mathrm{~m}$. Both the observations and the model have the inflow concentrated on the northern side of the channel, and the outflow near the center. Also, the maximum inflow (outflow) velocity from the model is close to the measured value of $14 \mathrm{~cm} \mathrm{~s}^{-1}\left(41 \mathrm{~cm} \mathrm{~s}^{-1}\right)$. By comparing Fig. $11 \mathrm{~b}$ with the results of the basic experiment (Fig. 4 ), it is evident that the maximum outflow velocities near the surface are about twice as large in the windforced case (expt D). The effect of the northwesterly wind on the estuarine circulation at the mouth of Juan de Fuca can be understood in light of previous work in which it was determined that such a wind is effective in pushing the freshwater plume out of the Strait of Georgia (e.g., Hickey et al. 1991). 


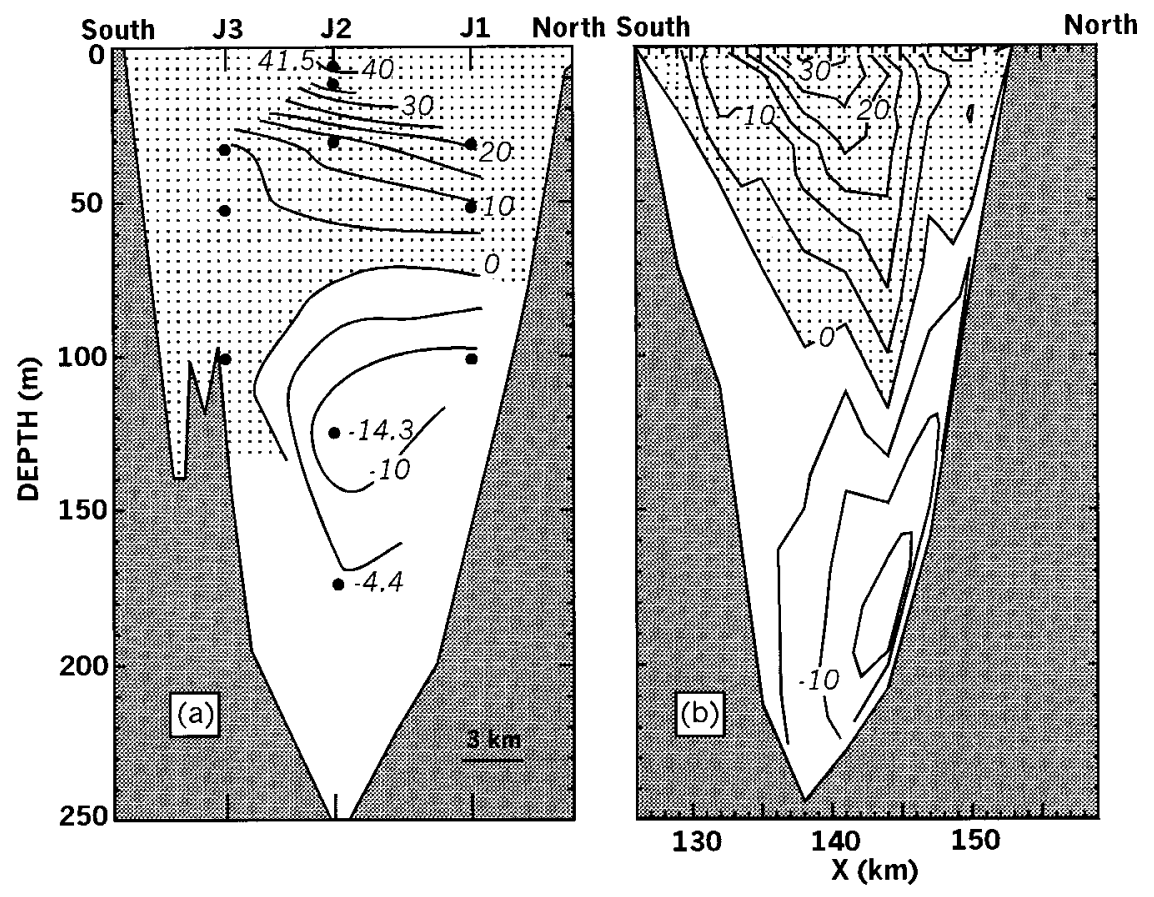

FIG. 11. Contours of summer-average alongshore velocities (in $\mathrm{cm} \mathrm{s}^{-1}$ ) across the mouth of Juan de Fuca Strait for (a) the currents measured during summer 1984 (after Hickey et al. 1991), and (b) the ones from experiment D (wind-forced case). The model currents are averages over a 30day period centered around the time of maximum alongshore transport of the coastal current.

Another source of data available for comparison with the modeled flow in Juan de Fuca comes from Godin et al. (1981). They present an analysis of current measurements taken in 1973, when an attempt was made to estimate the net transport in and out of the Strait of Georgia. Although their investigation could not provide a reliable estimate of the net transport, it did yield useful estimates of the volume transport in the upper and lower flows of Juan de Fuca Strait. From data collected in spring, they found mean transport values of about $9 \times$ $10^{4} \mathrm{~m}^{3} \mathrm{~s}^{-1}$ for both layers. The same quantity computed from the model output gives a similar transport of $8 \times$ $10^{4} \mathrm{~m}^{3} \mathrm{~s}^{-1}$ at the end of the initialization run (expt B). It may be noted that this volume transport represents about 30 times the river volume outflow.

During the last 20 years, many current meters were deployed along the path of the coastal current at various depths. To compare the spatial structure of the modeled current with the data, a series of current meter datasets was analyzed. For all stations, the same summer period was selected, from 21 June to 31 August, for which a mean current vector was computed. Most of the data used here were collected during the summer of 1984 (Hickey et al. 1991). The Fraser discharge for that year followed quite closely the average profile of Fig. 2a. To provide a more complete coverage, data collected in the late 1970s and early 1980s were also analyzed. For comparison with the field data, the model velocities from experiment D were averaged over a 30-day summer pe- riod around the time of maximum alongshore transport of the coastal current (as in Fig. 11b). The resulting velocity vectors are given in Fig. 12 at four different depths: 10, 30, 50, and $110 \mathrm{~m}$. Also included in the figure are the measured mean velocities for the corresponding instrument depths (within $10 \mathrm{~m}$ ).

At all four depths, the spatial structure of the modeled coastal current is in good agreement with the data. The coastal circulation induced by the freshwater comprises a strong estuarine exchange at the mouth of Juan de Fuca, a complicated pattern of currents over the wide shelf of La Pérouse Bank, and the coalescing of currents into a well-defined alongshore current north of Barkley Sound. Also, for both model and data, the core of the coastal current is located at a depth of about $30 \mathrm{~m}$. The model also indicates that the estuarine circulation in Juan de Fuca forces water to be upwelled through the Juan de Fuca canyon, in agreement with observations mentioned above in section 2. The magnitude of the velocity vectors within the buoyancy-driven current is, however, not as large in the model as in the data. This is particularly evident at the stations near Estevan Point (EE and E1). One possible reason for the relative weakness of the modeled current may be the choice of the buoyancy forcing. In the present model, the flow rate is taken as the discharge of the Fraser River measured at Hope. As mentioned in section $3 b$, this is a conservative value considering that the total freshet discharge flowing into the interior basins (Strait of Georgia, Juan 

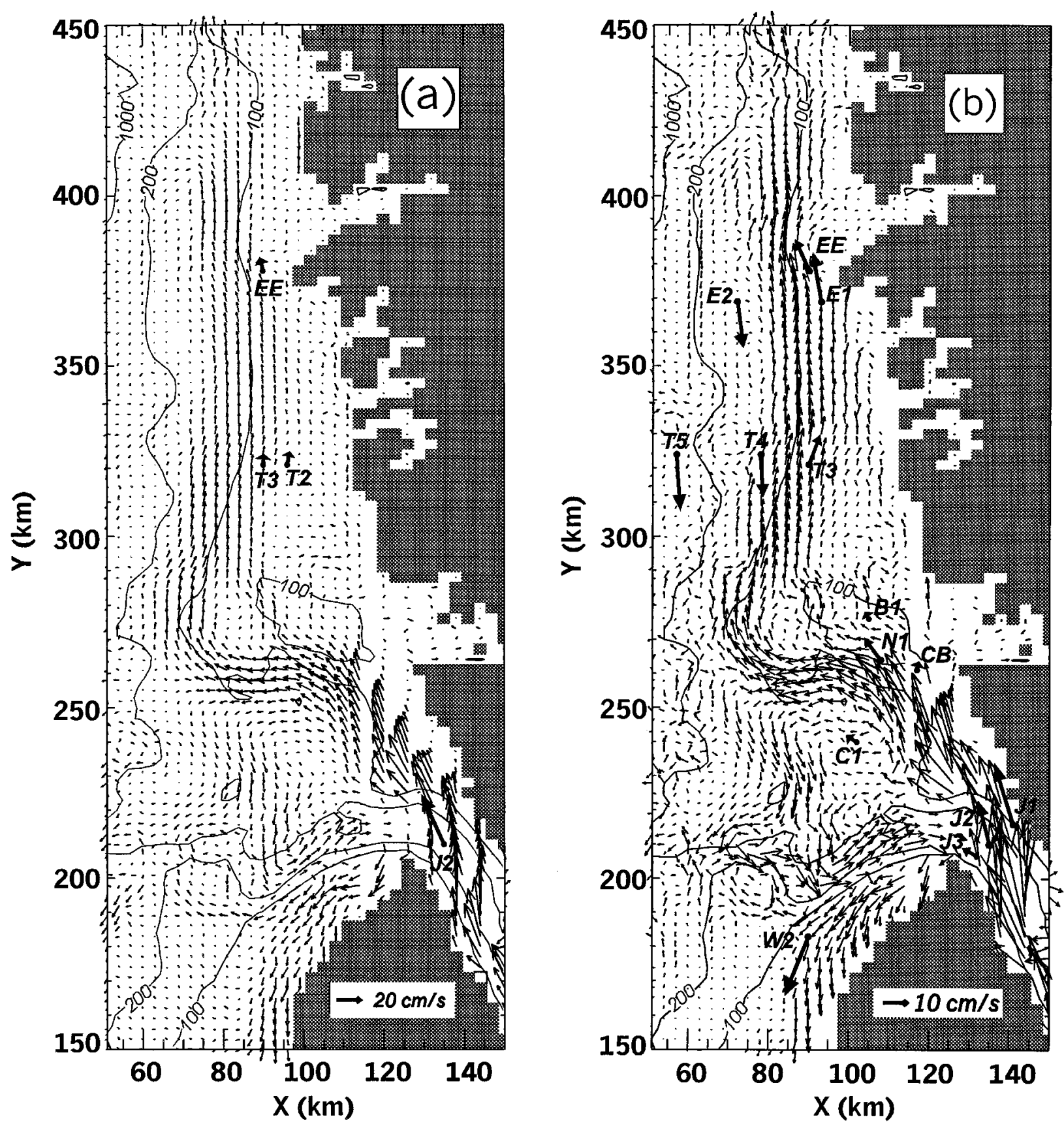

FIG. 12. Mean current vectors from the numerical model (thin arrows) and from current meter observations (thick arrows) for depths of 10 (a), 30 (b), 50 (c), and 110 (d) m. The model currents are time averaged as in Fig. 11b, and the current meter depths are within $10 \mathrm{~m}$ of the chosen depth levels.

de Fuca Strait, and Puget Sound) could be as high as three times that value (LeBlond et al. 1983).

In Fig. 12, the moorings deployed near the shelf break (Z3, T4, T5, E2) indicate a strong southeast current flowing equatorward with the seasonal summer wind. These stations are located within the wind-driven shelfbreak current mentioned in section 2 . The model results do not properly reproduce this relatively strong current.
This is likely a consequence of the absence of stratification in this area of the model. Due to the freshwater input, the water close to the coast becomes stratified under the influence of the plume. However, farther offshore, practically no stratification develops. This weak response of the homogeneous shelfbreak water to the upwelling favorable wind is in agreement with the findings of Allen et al. (1995). They examined the response 

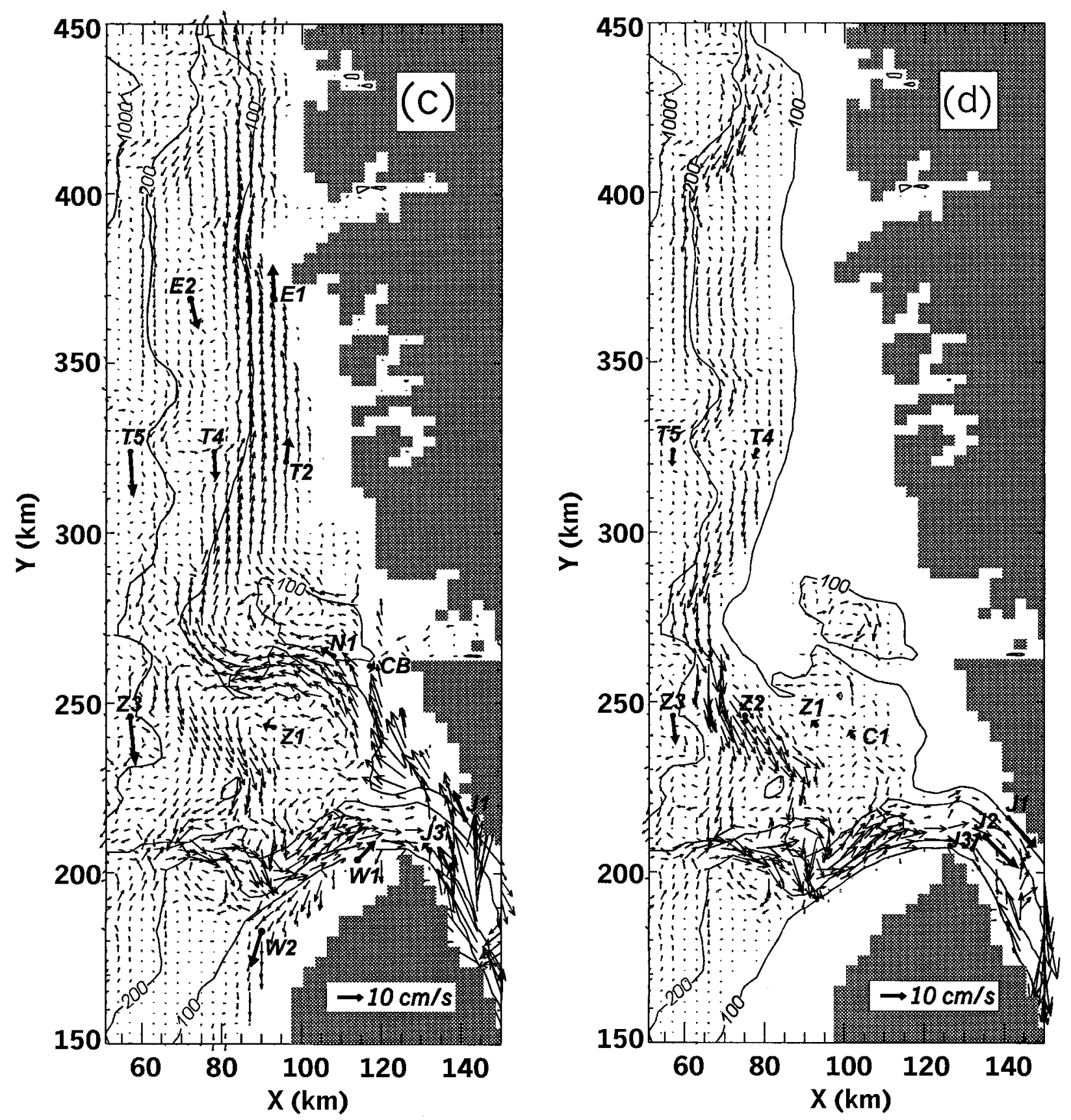

FIG. 12. (Continued)

of a two-dimensional coastal ocean to an upwelling wind and found that the strength of the wind-induced coastal jet greatly depends on the stratification and that, in the absence of stratification, the wind-induced coastal jet is virtually absent. On the other hand, at one station near the Washington coast (W2), a surface intensified, winddriven response is obtained. Under the influence of the wind, the river plume reaches the area and, in both the model and data, a relatively strong current flows with the wind.

\section{Summary}

In this study, a prognostic numerical model has been applied to study the influence of freshwater discharge into the Strait of Georgia on the summer circulation off the west coast of Vancouver Island. The model encompasses a wide area and, to our knowledge, is the first that includes a realistic representation of the inner coastal basins, the connecting channels and the continental shelf of this region. The Fraser River is the main source 
of freshwater during summer and is included in the model as a volume flux of zero salinity water. A series of numerical simulations was conducted to examine the formation of the poleward flowing Vancouver Island coastal current (VICC).

In the simplest simulation, the river discharges into a quiescent and homogeneous ocean. The volume flux is specified according to daily mean discharge values and passes through a summer freshet period. In response, a buoyant freshwater plume forms in the Strait of Georgia, which spreads through the narrow southern passages and mixes with the ambient water to form an estuarine circulation in Juan de Fuca Strait. In the open ocean near the mouth of the Strait, the low salinity outflow forms a bulge on the shelf from which a rightbounded current emerges and advances along the coast as a density intrusion that eventually extends the length of the island. In this simulation, the VICC appears first as a weak barotropic flow, upstream of the advancing front. The surface-intensified baroclinic structure of the current becomes established later, after the passage of the head of the intrusion. An analysis of the momentum balance shows that the depth-averaged flow of the coastal current is mostly driven by the alongshore barotropic pressure gradient and balanced by an opposing baroclinic pressure gradient and bottom friction.

Additional experiments examined the sensitivity of the response to the initial conditions, wind forcing, enhanced mixing within the estuary, and grid resolution. In an initialization run, a constant river discharge is specified and the model VICC is allowed to reach a quasi-steady state. From this point, the river discharge evolves according to the summer freshet. Under these conditions, the time lag between the maximum alongshore transport of the coastal current and the peak river discharge is governed mainly by a relatively short advection timescale set by the mean current, rather than the slower gravity current speed as in the basic experiment. The inclusion of a moderate northwesterly wind, representative of summer conditions, adds an additional element of realism to the simulations. The opposing wind reduces the transport of the VICC and forces the current maximum from the surface to a depth of about $30 \mathrm{~m}$, consistent with observations. Enhanced vertical mixing over a sill within the estuary modifies the water properties inside Juan de Fuca Strait and slows the advance of the density intrusion. However, the effects on the general characteristics of the coastal current away from the mouth of the estuary are minimal.

An extensive set of current meter observations was used to compare with the model results at the mouth of Juan de Fuca Strait and over the shelf. The spatial structure of the estuarine flow and the volume flux of low salinity water into the open ocean at the mouth of the strait in springtime (about 30 times the river discharge) compare favorably with observations. Also consistent with observations is the eastward flowing upwelling circulation, driven by the estuarine circulation in Juan de
Fuca canyon, which acts as a conduit for the deep inflow into the strait. Over the inner region of the shelf, the model currents have a pattern similar to the observations, but underestimate somewhat the magnitude of the mean summer countercurrent. This may be a consequence of using a conservative estimate of the total freshwater discharge into the inner basins. Over the shelf break, the absence of an ambient stratification prevents the model from capturing the observed surface intensification of the wind-driven equatorward current.

Future studies into the response of the coastal ocean to changes in the relative timing of the river freshet and the spring transition of the coastal winds now seem warranted. The incorporation of greater realism into the model will require inclusion of the open ocean stratification to model properly the wind-driven shelfbreak current and associated upwelling. Also, including tidally modulated mixing would allow simulation of the observed pulses of fresh surface water in Juan de Fuca Strait.

Acknowledgments. We thank Lie-Yauw Oey for providing his version of the Princeton Ocean Model. Most of the current meter data used in this study were collected in 1984 under the direction of B. M. Hickey, R. E. Thomson, and P. H. LeBlond. Some data were collected during the 1979 CODE experiment by H. J. Freeland. We are grateful to Prof. Brian T. Newbold for proofreading the manuscript.

\section{REFERENCES}

Allen, J. S., P. A. Newberger, and J. Federiuk, 1995: Upwelling circulation on the Oregon continental shelf. Part 1: Response to idealized forcing. J. Phys. Oceanogr., 25, 1843-1889.

Blumberg, A. F., and G. L. Mellor, 1987: A description of a threedimensional coastal ocean circulation model. Three Dimensional Coastal Ocean Models, N. Heaps, Ed., Coastal and Estuarine Science Series, Vol. 4, Amer. Geophys. Union, 1-16.

Chao, S. Y., 1987: Wind-driven motion near inner-shelf fronts. J. Geophys. Res., 92, 3849-3860.

- , and B. C. Boicourt, 1986: Onset of estuarine plumes. J. Phys. Oceanogr., 16, 2137-2149.

Crean, P. B., and A. B. Ages, 1971: Oceanographic records from twelve cruises in the Strait of Georgia and Juan de Fuca Strait, 1968. Department of Energy, Mines, and Resources, Marine Research Sciences Branch, Vols. 1-4, 389 pp. [Available from A. Ages, Institute of Ocean Sciences, P.O. Box 6000, 9860 W. Saanich Rd., Sidney, BC, V8L 4B2, Canada.]

Csanady, G. T., 1978: The arrested topographic wave. J. Phys. Oceanogr., 8, 47-62.

Foreman, G. G., and R. E. Thomson, 1997: Three-dimensional model simulations of tides and buoyancy currents along the west coast of Vancouver Island. J. Phys. Oceanogr., 27, 1300-1325.

Freeland, H. J., and K. L. Denman, 1982: A topographically controlled upwelling center off southern Vancouver Island. J. Mar. Res., 40, 1069-1093.

—, W. R. Crawford, and R. E. Thomson, 1984: Currents along the Pacific Coast of Canada. Atmos.-Ocean, 22, 151-172.

Godin, G., J. Candela, and R. de la Paz-Vela, 1981: On the feasibility of detecting net transports in and out of Georgia Strait with an array of current meters. Atmos.-Ocean, 19, 148-157.

Griffin, D. A., and P. H. LeBlond, 1990: Estuary/ocean exchange 
controlled by spring-neap tidal mixing. Estuarine Coastal Shelf Sci., 30, 275-297.

Hickey, B. M., R. E. Thomson, H. Yih, and P. H. LeBlond, 1991: Velocity and temperature fluctuations in a buoyancy-driven current off Vancouver Island. J. Geophys. Res., 96, $10507-10538$

Kourafalou, V. H., L.-Y. Oey, J. D. Wang, and T. N. Lee, 1996: The fate of river discharge on the continental shelf. 1: Modeling the river plume and the inner shelf coastal current. J. Geophys. Res., 101, 3415-3434.

LeBlond, P. H., K. Dyck, K. Perry, and D. Cumming, 1983: Runoff and precipitation time series for the coasts of British Columbia and Washington State. Dept. of Oceanography, University of British Columbia Rep. 39, 133 pp.

Mellor, G. L., and T. Yamada, 1982: Development of a turbulent closure model for geophysical fluid problems. Rev. Geophys. Space Phys., 20, 851-875.

- T. Ezer, and L. Y. Oey, 1994: The pressure gradient conundrum of sigma coordinate ocean models. J. Atmos. Oceanic Technol., 11, 1126-1134.
Oey, L. Y., 1996: Simulation of mesoscale variability in the Gulf of Mexico: Sensitivity studies, comparison with observations, and trapped wave propagation. J. Phys. Oceanogr., 26, 145-175.

— , and P. Chen, 1992: A model simulation of circulation in the northeast Atlantic shelves and seas. J. Geophys. Res., 97, $20087-20115$.

Pal, B. K., and G. Holloway, 1996: Dynamics of circulation off the west coast of Vancouver Island. Contin. Shelf Res., 16, 15911607.

Stronach, J. A., J. O. Backhaus, and T. S. Murty, 1993: An update on the numerical simulation of oceanographic processes in the waters between Vancouver Island and the mainland: The GF8 model. Oceanogr. Mar. Biol. Annu. Rev., 31, 1-86.

Thomson, R. E., B. M. Hickey, and P. H. LeBlond, 1989: The Vancouver Island coastal current: Fisheries barrier and conduit. Effects of ocean variability on recruitment and an evaluation of parameters used in stock assessment models. Can. Spec. Publ. Fish. Aquat. Sci., 108, 265-296. 